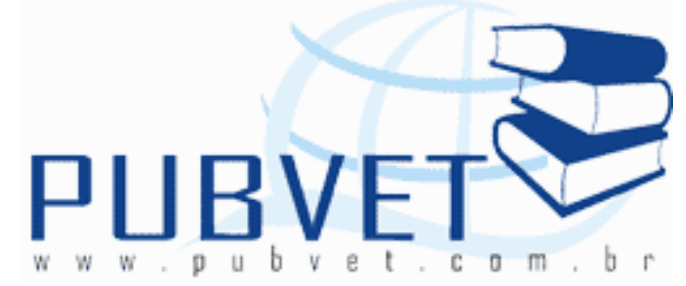

PUBVET, Publicações em Medicina Veterinária e Zootecnia.

\title{
Níveis de fitase em dietas para frangos de corte: avaliação da disponibilidade do fósforo
}

Elvania Maria da Silva Costa ${ }^{1}$, Agustinho Valente de Figueirêdo ${ }^{2}$, Tyssia de Sousa Alves ${ }^{3}$, Domingos Urquiza de Carvalho Filho ${ }^{4}$, Antônio de Carvalho Pereira $^{5}$, Tatiele Pereira Araújo ${ }^{3}$

\footnotetext{
${ }^{1}$ Mestranda do Programa de Pós-Graduação em Ciência Animal - UFPI. E-mail para correspondência: ellvania@hotmail.com

${ }^{2}$ Professor do Departamento de Zootecnia - UFPI

${ }^{3}$ Graduanda do curso de Medicina Veterinária - UFPI

${ }^{4}$ Doutorando do Programa de Pós-Graduação em Ciência Animal - UFPI

${ }^{5}$ Graduando do curso de Engenharia Agronômica - UFPI
}

\section{Resumo}

Objetivou-se avaliar o efeito de níveis da enzima fitase em dietas, sobre a deposição de fósforo na carcaça de frangos de corte no período de 1 a 21 dias de idade. Foram utilizados 200 pintos da linhagem comercial Ross, de um dia de idade, de ambos os sexos, distribuídos em delineamento inteiramente ao acaso com os tratamentos consistindo de cinco níveis de enzima fitase ( 0 , $1000,2000,3000$ e 4000 FTU/kg), com quatro repetições. A unidade experimental foi representada por 10 aves/ box. Aos 21 dias de idade, foram abatidos um frango por unidade experimental, com peso corporal próximo da média, sendo analisados as carcaças quanto ao percentual de fósforo 
inorgânico total em matéria natural, por via úmida. A deposição de fósforo na carcaça de frangos de corte não foi afetada pelos níveis de fitase nas rações, com média de 1,698\%. O aumento dos teores de fitase em dietas para frangos de corte, não afeta a deposição de fósforo nas carcaças das aves no período de 1 a 21 dias de idade.

Palavras-chave: avaliação de carcaça, deposição de fósforo, enzima fitase.

\title{
Phytase levels in diets for broiler: evaluation of the availability of phosphorus
}

\begin{abstract}
This study aimed to evaluate the effect of levels of phytase in diets on phosphorus deposition in the carcass of broilers during 1-21 days of age. We used 200 chicks of commercial strain Ross, a day old, of both sexes distributed in a completely randomized design with treatments consisting of five levels of phytase $(0,1000,2000,3000$ and $4000 \mathrm{FTU} / \mathrm{kg}$ ) with four replications. The experimental unit was represented by 10 birds / box. At 21 days old, were slaughtered chicken for an experimental unit, weighting around the average, the carcasses were analyzed in terms of percentage of total inorganic phosphorus on natural wet. Phosphorus deposition in the carcass of broilers was not affected by levels of phytase in the diet, with an average of $1.698 \%$. The increased levels of phytase in diets for broilers, does not affect the deposition of phosphorus in carcasses of the birds from 1 to 21 days old.
\end{abstract}

Keywords: carcass evaluation, phosphorus availability, phytase enzyme.

\section{INTRODUÇÃO}

O fósforo é considerado um dos mais importantes minerais exigidos pelas aves, todo processo de síntese, conectado com o crescimento e produção, formação do esqueleto, aumento de massa muscular, formação de ovos, dentre outros aspectos, envolve compostos de ácido fosfórico, todavia, em 
torno de $70 \%$ desse mineral, nas rações compostas de grãos de cereais encontra-se na forma de ácido fítico, formando fitato (inositol hexafosfato).

O fitato é um fator antinutricional para monogástricos, possuindo em sua estrutura grupos ortofosfatos altamente ionizáveis, os quais afetam a disponibilidade de aminoácidos e cátions bivalentes como o cálcio, zinco, cobre, magnésio, manganês e ferro no trato gastrointestinal, o que resulta na formação de complexos insolúveis.

Os animais monogástricos não aproveitam o fósforo fítico por não sintetizarem a enzima fitase no trato gastrointestinal e no grão, o nível de fitase é baixo, portanto, sua suplementação se faz necessária em dietas para frangos de corte (Pizzolante; Teixeira; Santos, 2002) a fim de hidrolisar o fitato e liberar o fósforo e outros nutrientes para absorção. Assim, a adição de fitase tem sido uma alternativa para melhorar a disponibilidade de fósforo e de outros minerais, bem como, a digestibilidade de proteínas e carboidratos dos alimentos de origem vegetal (Silva et al., 2006; Laurentiz et al., 2009).

Na criação de frangos de corte, ao formular rações, é necessário a adição de fosfatos, que chegam a atingir até $50 \%$ das despesas com suplementos minerais e vitamínicos. O suprimento adequado de fósforo nas dietas evita desperdícios; contribui para melhorar o desempenho do plantel; aumenta sua deposição nos ossos, o que minimiza os problemas de pernas, e reduz a descarga de poluente no solo decorrente do fósforo não absorvido pelo organismo, excretado com os dejetos.

Com este experimento, objetivou-se avaliar os efeitos da inclusão de níveis de fitase em dietas, sobre a deposição de fósforo na carcaça de frangos de corte no período de 1 a 21 dias de idade.

\section{MATERIAL E MÉTODOS}

O experimento foi desenvolvido no galpão do Setor de Avicultura do Departamento de Zootecnia (DZO) do Centro de Ciências Agrárias (CCA) da Universidade Federal do Piauí (UFPI), em Teresina, Piauí e as análises de fósforo inorgânico total foram determinadas na Embrapa Meio-Norte. 
Foram utilizados 200 pintos da linhagem comercial Ross, de um dia de idade, de ambos os sexos, distribuídos em delineamento inteiramente ao acaso com os tratamentos consistindo de cinco níveis de enzima fitase $(0,1000$, 2000, 3000 e $4000 \mathrm{FTU} / \mathrm{kg}$ ), com quatro repetições. A unidade experimental foi representada por 10 aves/ box. O monitoramento da temperatura e umidade relativa do ar foram realizadas diariamente por meio de termohigrômetros de máxima e mínima mantidos no interior do galpão. 0 programa de luz adotado foi por 24 horas (natural ou artificial) e aquecimento dos pintinhos por lâmpadas incandescentes de 100 w. Nos períodos do dia em que a temperatura ultrapassou a zona de termoneutralidade, foram acionados ventiladores para minimizar o estresse por calor.

As dietas experimentais (Tabela 1 ) foram formuladas para o período de 1 a 21 dias de forma a atender as exigências nutricionais das aves de acordo com Rostagno et al. (2005).

Aos 21 dias de idade, selecionou-se um frango por parcela experimental, com peso corporal próximo da média, foram identificados, pesados individualmente e abatidos. As carcaças (com pés e cabeça) foram submetidas à pré-secagem em estufa de circulação de ar forçada a $65^{\circ} \mathrm{C}$ por 72 horas, posteriormente foram moídas até obter a granulometria necessária às análises de fósforo. A determinação de fósforo inorgânico total na matéria natural foi realizada por via úmida, conforme metodologia adaptada de Silva; Queiroz (2005).

Os resultados foram submetidos à análise de variância, pelo procedimento GLM do programa SAS (1997), e as médias comparadas pelo teste de Duncan. 
Tabela 1- Composição das dietas experimentais, em função dos níveis de fitase, para o período 1 a 21 dias de idade

\begin{tabular}{lccccc}
\hline \multirow{2}{*}{ Ingredientes (\%) } & \multicolumn{5}{c}{ Níveis de fitase nas dietas (FTU/kg) } \\
\cline { 2 - 6 } & 0 & 1.000 & 2.000 & 3.000 & 4.000 \\
\hline Milho & 55,400 & 55,400 & 55,400 & 55,400 & 55,400 \\
Farelo de soja & 37,130 & 37,130 & 37,130 & 37,130 & 37,130 \\
Óleo Vegetal & 3,280 & 3,280 & 3,280 & 3,280 & 3,280 \\
Fosfato bicálcico & 1,820 & 1,820 & 1,820 & 1,820 & 1,820 \\
Calcário calcítico & 0,985 & 0,985 & 0,985 & 0,985 & 0,985 \\
NaCl & 0,480 & 0,480 & 0,480 & 0,480 & 0,480 \\
Premix mineral e vitamínico & 0,800 & 0,800 & 0,800 & 0,800 & 0,800 \\
Material inerte & 0,100 & 0,090 & 0,080 & 0,070 & 0,060 \\
Enzima & 0,000 & 0,010 & 0,020 & 0,030 & 0,040 \\
Total & 100,00 & 100,00 & 100,00 & 100,00 & 100,00 \\
\hline Nutrientes & \multicolumn{5}{c}{ Valores Calculados } \\
\hline PB (\%) & 21,40 & 21,40 & 21,40 & 21,40 & 21,40 \\
EM (kcal/kg) & 2999,04 & 2999,04 & 2999,04 & 2999,04 & 2999,04 \\
Ca (\%) & 0,96 & 0,96 & 0,96 & 0,96 & 0,96 \\
Pd (\%) & 0,45 & 0,45 & 0,45 & 0,45 & 0,45 \\
Lis (\%) & 1,16 & 1,16 & 1,16 & 1,16 & 1,16 \\
Met+Cist (\%) & 0,83 & 0,83 & 0,83 & 0,83 & 0,83 \\
Na (\%) & 0,21 & 0,21 & 0,21 & 0,21 & 0,21 \\
\hline
\end{tabular}

1 Conteúdo por kg de ração: Vitamina A - 1.500.000 UI; Vitamina D3 266.670 UI; Vitamina E - 2.333 mg; Vitamina K3 - 250 mg; Vitamina B1 166,67 mg; Vitamina B6 - 300 mg; Vitamina B12 -2000 mcg; Niacina -5.000 $\mathrm{mg}$; Pantotenato de calico - $1.500 \mathrm{mg}$; Ácido fólico - $50 \mathrm{mg}$; Biotina - 83,3 mg; Ferro - 5.000 mg; Cobre- 1.500 mg; Manganês - 10.000 mg; Zinco $10.000 \mathrm{mg}$; iodo -166,67 mg; Selênio - 41,67 mg; Colina - 36.540 mg; Metionina 344,91 g; Lisina - 71, $627 \mathrm{~g}$; Halquinol (promotor de crescimento) - $5.000 \mathrm{mg}$; Salinomicina - $11.000 \mathrm{mg}$. 


\section{RESULTADOS E DISCUSSÃO}

Foram registradas temperaturas máximas de 29,55 $\pm 0,66^{\circ} \mathrm{C}$ e umidade relativa do ar de $73,1 \% \pm 2,75$ no período de 1 a 21 dias de idade, condições estas que de acordo com Baêta; Souza (1997) está dentro da zona de conforto térmico das aves.

Na determinação de fósforo inorgânico total em matéria natural (Tabela 2 ), observa-se que os valores médios do teor de fósforo nas carcaças de frangos de corte, não foram afetados $(P>0,05)$ pela inclusão dos níveis de fitase nas dietas.

Tabela 2- Deposição de fósforo $(P)$ na carcaça de frangos de corte no período de 1 a 21 dias de idade em função dos níveis de fitase

\begin{tabular}{lc}
\hline Níveis de fitase (UFT/Kg da dieta) & $\mathrm{P}(\%)$ \\
\hline 0 & 1,3950 \\
1.000 & 1,8325 \\
2.000 & 1,9425 \\
3.000 & 1,9275 \\
4.000 & 1,9925 \\
\hline CV (\%) & 31,20 \\
\hline REGRESSÃO & $\mathrm{NS}$
\end{tabular}

Tendo em vista que as dietas experimentais foram formuladas visando atender as exigências nutricionais em fósforo para frangos de corte no período de 1 a 21 dias, Schoulten et al. (2003) relata que a maior capacidade de hidrolisar o fitato é quando as aves consomem níveis de fósforo abaixo do exigido, sendo necessário manter os níveis deste mineral nos limites mínimos, com isso, sugere-se que os níveis de fósforo devem ser reduzidos quando a fitase for utilizada na formulação das dietas. 
Observou-se que não houve incorporação do fósforo na carcaça das aves, no entanto, a dieta controle atendeu as exigências deste mineral, assim, possivelmente a inclusão de fitase às dietas proporcionou excesso de fósforo disponível, o que pode ter aumentado as perdas de fósforo nas excretas.

Outro aspecto importante a considerar é o nível de enzima a ser adicionado, que deve está de acordo com o nível de redução nutricional estabelecido. A ação da fitase é dose dependente, e aumenta à medida que níveis mais altos são adicionadas à dieta. Em contrapartida, à medida que os níveis nutricionais são reduzidos abaixo da exigência do animal, ocorre naturalmente, uma maior retenção do nutriente pelo organismo para que sejam mantidas as funções fisiológicas, no entanto, níveis mais altos de fitase podem ser necessários para que seja expresso o efeito da enzima.

\section{CONCLUSÕES}

O aumento dos teores de fitase em dietas para frangos de corte, não afeta a deposição de fósforo nas carcaças das aves no período de 1 a 21 dias de idade.

\section{REFERÊNCIAS BIBLIOGRÁFICAS}

BAÊTA, F. C.; SOUZA, C. F. Ambiência em edificações rurais, conforto animal. Viçosa, MG: Universidade Federal de Viçosa, 1997. 246p.

LAURENTIZ, A. C. et al. Desempenho, composição da cama, das tíbias, do fígado e das excretas de frangos de corte alimentados com rações contendo fitase e baixos níveis de fósforo. Revista Brasileira de Zootecnia, v.38, n.10, p.1938-1947, 2009.

PIZZOLANTE, C. C.; TEIXEIRA, A. S.; SANTOS, C. D. Utilização da fitase na alimentação de frangos de corte: desempenho. In: CONFERÊNCIA APINCO 2000 DE CIÊNCIA E TECNOLOGIA AVÍ́COLAS, 2000, Campinas. Anais... Campinas: FACTA, p. 45, 2002.

ROSTAGNO, H. S. et al. Tabelas brasileiras para aves e suínos: composição de alimentos e exigências nutricionais. Viçosa, MG: UFV, 2005, 252p.

SAS. Statistical analysis systems user's guide: Cary, NC, USA: SAS Institute Inc., 1997. 
SCHOULT, A. N. et al. Efeito dos níveis de cálcio da ração suplementadas com fitase sobre a deposição de minerais na tíbia de frangos de corte de 22 a 42 dias. Ciência Agrotécnica, v.27, n.1, p.206-210. 2003.

SILVA, D. J.; QUEIROZ, A. C. Análise dos Alimentos (Métodos químicos e biológicos). 3. ed., Viçosa: Universidade Federal de Viçosa. 235p, 2005.

SILVA, Y.L. et al., Redução de proteína e fósforo em rações com fitase para frangos de corte no período de 1 a 21 dias de idade. Desempenho e teores de minerais na cama. Revista Brasileira de Zootecnia, v.35, n.3, p.840-848, 2006. 